\section{A sustainable wood biorefinery for low-carbon footprint chemicals production}

\author{
Yuhe Liao ${ }^{1 *}$, Steven-Friso Koelewijn ${ }^{1}$, Gil Van den Bossche ${ }^{1}$, Joost Van Aelst ${ }^{1}$, Sander Van den Bosch ${ }^{1}$, \\ Tom Renders ${ }^{1}$, Kranti Navare ${ }^{2}$, Thomas Nicolai ${ }^{3}$, Korneel Van Aelst ${ }^{1}$, Maarten Maesen ${ }^{4}$, \\ Hironori Matsushima ${ }^{4}$, Johan M. Thevelein ${ }^{3}$, Karel Van Acker ${ }^{2,5}$, Bert Lagrain ${ }^{1}$, \\ Danny Verboekend ${ }^{1}+$, Bert F. Sels ${ }^{1 *}$
}

The profitability and sustainability of future biorefineries are dependent on efficient feedstock use. Therefore, it is essential to valorize lignin when using wood. We have developed an integrated biorefinery that converts 78 weight \% (wt \%) of birch into xylochemicals. Reductive catalytic fractionation of the wood produces a carbohydrate pulp amenable to bioethanol production and a lignin oil. After extraction of the lignin oil, the crude, unseparated mixture of phenolic monomers is catalytically funneled into 20 wt \% of phenol and 9 wt \% of propylene (on the basis of lignin weight) by gas-phase hydroprocessing and dealkylation; the residual phenolic oligomers (30 wt \%) are used in printing ink as replacements for controversial para-nonylphenol. A techno-economic analysis predicts an economically competitive production process, and a life-cycle assessment estimates a lower carbon dioxide footprint relative to that of fossil-based production.

P hotosynthetic carbon capture by plant biomass, as evidenced by the global tree cover potential of 4.4 billion hectares of canopy, is likely to be among the most effective strategies for climate change mitigation (I). With an average annual production of $\sim 10$ metric tons of dry biomass per hectare (2), such nonedible biomass represents an abundant feedstock of renewable carbon worldwide and is a prime candidate to sustainably produce fuels, chemicals, and materials $(3,4)$. Climate change mitigation through global forest restoration has the potential to capture more than 200 billion tons of additional carbon at maturity, thereby reducing atmospheric carbon by about $25 \%$ (1). Together with the exploitation of underused biomass, reforestation will increase future lignocellulose availability and offers great potential for an abundant and inexpensive supply of renewable carbon, provided that production and processing are sustainable.

Petrochemicals are set to become the largest driver of global oil consumption in the future $(5,6)$. A shift from fossil to renewable carbon resources can decouple chemical production from fossil resources and the resulting $\mathrm{CO}_{2}$ emissions. However, to be cost and environmentally competitive with fossil-based processes, it

\footnotetext{
${ }^{1}$ Center for Sustainable Catalysis and Engineering, $\mathrm{KU}$ Leuven, Celestijnenlaan 200F, 3001 Heverlee, Belgium. ${ }^{2}$ Department of Materials Engineering, KU Leuven, Kasteelpark Arenberg 44, 3001 Leuven, Belgium. ${ }^{3}$ Laboratory of Molecular Cell Biology, KU Leuven, and Center for Microbiology, VIB, Kasteelpark Arenberg 31, 3001 Heverlee Belgium. ${ }^{4}$ Lawter bvba, Ketenislaan 1C, Haven 1520, 9130 Kallo, Belgium. ${ }^{5}$ Center for Economics and Corporate Sustainability, KU Leuven, Warmoesberg 26, 1000 Brussels, Belgium.

*Corresponding author. Email: bert.sels@kuleuven.be (B.F.S); yuhe.liao@kuleuven.be or yuhe.liao20@gmail.com (Y.L.) †Present address: Zeopore Technologies NV, Lelielaan 4, 3061 Bertem, Belgium.
}

and hydrogenolysis either in batch or in (semi-)continuous mode over a metal catalyst in the presence of a reducing agent, such as hydrogen. The general consensus is that stabilization of the reactive intermediates formed by depolymerization of in planta lignin prevents formation of unreactive condensed lignin derivatives (14). Near-complete delignification of hardwoods, such as birch and poplar, can be achieved without notable carbohydrate degradation (16). Besides low-molecular weight oligomers, the lignin oil contains few phenolic monomers in close-to-theoretical yields, namely $50 \mathrm{wt} \%$ for hardwoods (16). However, maximal valorization of lignin oil into highvalue products, such as phenol, by technology that is profitable-but more importantly, sustainable-is key in demonstrating the potential of wood biorefineries.

The high yield of structurally similar phenolic monomers from the conversion of wood lignin prompted us to design a process for their transformation toward phenol and propylene by catalytic funneling (fig. S4 and supplementary text ST2). A typical composition of phenolic monomers (50.5 wt \% on lignin weight basis; Fig. 2A and details in table S1) after RCF of birch wood in methanol over commercial $\mathrm{Ru} / \mathrm{C}$ includes 4- $n$-propylguaiacol (PG; $19 \mathrm{wt} \%$ ) and 4- $n$-propylsyringol (PS; $67 \mathrm{wt} \%$ ) as major components, and others including 4-ethylguaiacol (EG) and 4-ethylsyringol. Pine wood gives a yield of $14.1 \mathrm{wt} \%$ of monomers because of a lower delignification and depolymerization efficiency. Although para-alkyl substituents are dominant in the monomers, considerably more polar groups, such as primary alcohols, remain in the oligomers (figs. $\mathrm{S} 5$ and $\mathrm{S6}$, tables $\mathrm{S} 2$ and $\mathrm{S} 3$, and supplementary text ST3). This polarity difference facilitates the isolation of distinct monomers through a simple extraction in $n$-hexane under reflux (supplementary text ST4). This work demonstrates that a less-than-sixfold mass of $n$-hexane to lignin oil allows the cost-efficient extraction of more than $90 \mathrm{wt} \%$ of the lignin monomers (fig. S7). This procedure provides an optimum trade-off between extraction efficiency, solvent usage, and oligomer coextraction. Additional separations of individual phenolic monomers are not necessary because the crude monomeric extract can be catalytically funneled to the two products of interest, phenol and propylene.

To do so, the crude mixture of monomers was first chemo-catalytically hydroprocessed into $n$-propylphenols (PPs) and ethylphenols (EPs). In contrast to previously reported approaches using (batch) liquid-phase and/or sulfided catalysts on pure compounds (17-20), we pursued a solvent- and sulfur-free, continuous catalytic gas-phase hydroprocessing step. This procedure avoids product contamination as well as additional costs related to solvent loss and recovery. To establish the catalytic requirements 
for this selective hydroprocessing step, we initially studied commercially available PG, a representative monomer of the RCF lignin oil. The catalytic study explored several commercial metal catalysts (fig. S8). Non-noble metal Ni catalysts showed the highest PPs selectivity against other metals (figs. S8 and S9 and supplementary text ST5). Given the absence of a selectivity loss upon increased $\mathrm{Ni}$ content (Fig. 2, fig. S8B, and supplementary text ST5), highly loaded, well-dispersed Ni catalysts are preferred because of their high catalytic activity (Fig. 2B). Acidic supports (e.g., silica-alumina) led to more undesirable (propyl)cresols (vide infra), whereas redox-active supports (e.g., anatase $\mathrm{TiO}_{2}$ ) favored fully deoxygenated products such as $n$-propylbenzene and $n$-propylcyclohexane (fig. S8). Therefore, $\mathrm{Ni}$ is preferably supported on inert materials such as silica (fig. S8 and supplementary text ST5). After optimization, a $64 \mathrm{wt} \%$ of $\mathrm{Ni}$ on silica ( $64 \mathrm{wt} \% \mathrm{Ni} / \mathrm{SiO}_{2}$ ) catalyst reached $84 \%$ yield for PPs and EPs at a productivity of $4.5 \mathrm{~kg} \mathrm{~kg}^{-1}$ hour $^{-1}$ (figs. S8 and S10 to S12 and supplementary text ST6). Side products included mainly $n$-propylbenzene and propylcresols and minor amounts of other compounds, such as cresols and $n$-propylanisole (fig. S9). $\mathrm{Ni} / \mathrm{SiO}_{2}$ (64 wt \%) showed slight deactivation but without loss of selectivity after 72 hours at $285^{\circ} \mathrm{C}$ (Fig. 2D). The catalytic performance can be restored by a reduction treatment (fig. S13).

Next, we investigated the hydroprocessing of analytically pure representatives of lignin oil monomers other than PG, such as EG, isoeugenol, and PS (the most abundant monomer). For each compound, we observed high selectivity (75 to $85 \%$ ) toward PPs and EPs at (near) complete conversion (Fig. 2E and fig. S14). Removal of both methoxy moieties in PS demanded a longer contact time at a higher temperature, achieving a selectivity for PPs and EPs of $77 \%$ at full conversion. This notable ver- satility in substrates is pivotal to the concept of funneling and, hence, to the proposed ligninto-phenol strategy, that is, maximal conversion of different methoxylated alkylphenols to phenol (and propylene or ethylene). Kinetic studies showed that PG and 3-methoxyl-5- $n$ propylphenol were the key intermediates of PS hydroprocessing (Fig. 2E and fig. S14D). Furthermore, a detailed study on the dominant reaction pathways revealed the involvement of both demethoxylation and tandem demethylation-dehydroxylation pathways (figs. S15 to S18 and supplementary text ST7).

We ultimately moved to the hydroprocessing of a crude, unseparated mixture of monomers derived from RCF of pine and birch wood (Fig. 2E). At close-to-full conversion (>90\%), the selectivity to PPs and EPs was similarly high for both crude monomer mixtures, yielding a quasi-identical products distribution compared with the reactions on pure compounds under the same conditions (Fig. 2E, fig. S19, and table S4). Thus, $64 \mathrm{wt} \% \mathrm{Ni} / \mathrm{SiO}_{2}$ is robust to impurities (e.g., 4-methylsyringol) related to biomass feedstock. Gas chromatographic analysis showed that methoxy cleavage formed methane $/ \mathrm{H}_{2} \mathrm{O}$ and no $\mathrm{CO} / \mathrm{CO}_{2}$ (fig. S20). Analysis of the liquid condensate, obtained after condensing the gas-phase hydroprocessing products, confirmed the presence of mainly PPs and EPs with minor side products, such as (propyl) cresols and $n$-propylbenzene in addition to water (table S4 and fig. S21). This crude liquid condensate is used directly in the next dealkylation step without intermediate separation or purification.

We previously reported stable continuous gas-phase dealkylation of analytically pure alkylphenols (i.e., 4- $n$-propylphenol and 4-ethylphenol) to phenol and olefins over a commercial microporous ZSM-5 zeolite (21). Cofeeding of water was crucial to maintain robust catalytic activity (22), and hence the presence of water in the liquid alkylphenol condensate-formed during hydroprocessing-is beneficial. Given the higher complexity of the crude alkylphenol stream (e.g., impurities and bulkier molecules; table S4), we anticipated that an identical commercial ZSM-5 would be inadequate because of site-access restriction and coke formation (fig. S22 and supplementary text ST8.1). To overcome these concerns, we developed a tailormade hierarchical ZSM-5 (Z140-H) catalyst with a balanced network of micro- and mesopores (figs. S22 and S24 and table S5). With this catalyst, we observed near-quantitative and selective dealkylation of the crude alkylphenol condensates, giving a combined yield for phenol and olefines of $82 \%$ at high temperatures (Fig. 2, $\mathrm{F}$ and $\mathrm{G}$, and figs. S25 and S26). We assessed the stability of Z140-H (deliberately at incomplete conversion) for biomass-derived crude alkylphenol streams (Fig. 2F and fig. S27). Side products were cresols, benzene, and trace amount of a few others (figs. S28 and S29 and Fig. 2G). Cresols after separation can be selectively converted to phenol over USY (rather than ZSM5) through bimolecular reactions (fig. S30 and supplementary text ST8.2). Investigation of the product formation routes revealed the involvement of carbenium chemistry, including isomerization, disproportionation, transalkylation, and C-C cracking (fig. S31). Detailed kinetic studies (on 4-iPMP, PPs, EPs, and $n$ propylbenzene) demonstrated that zeolite hierarchization is key for the activity and/or stability (figs. S32 to S35 and supplementary text ST8). Zeolites with large micropores, such as USY, although capable of converting sterically demanding alkylphenols, lack the (transitionstate) pore confinement for shape-selective conversion. Confinement of the micropores, such

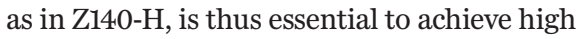
selectivity.

This gas-phase technology enables the catalytic funneling of crude (unseparated) mixture

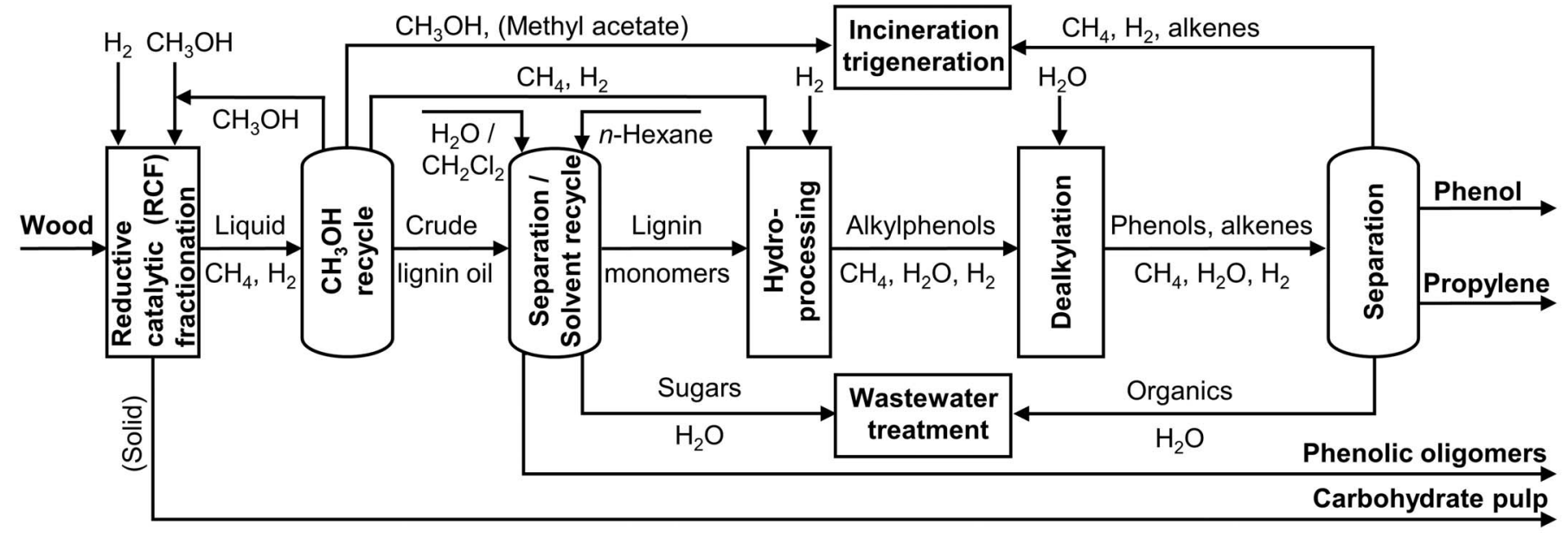

Fig. 1. Proposed integrated biorefinery process for xylochemicals production from wood. Flow diagram of the chemical process to produce carbohydrate pulp, phenol, propylene, and phenolic oligomers from wood. 
of lignin monomers (extracted from the RCF lignin oil) into bio-phenol and bio-propylene with 20 and 9 wt \% yields, respectively, on birch wood lignin weight basis (fig. S37). Using lignin monomers of pine wood yields lower amounts of phenol and propylene-6 and $3 \mathrm{wt} \%$, respectively-because of a lower delignification and depolymerization efficiency of RCF with softwoods. Therefore, hardwoods, such as birch, are the preferred feedstock for producing phenol and propylene. The markets for these two (drop-in) xylochemicals are well established (fig. S1), so they can be directly supplied with renewable substitutes. Currently, the largest share of phenol flows into bisphenol A (BPA) production. Nonetheless, anticipating a future, post-BPA era, bio-phenol may be better employed for producing bio-aniline (via ammonolysis) and bio-caprolactam in exist- ing facilities. Given the current uncertainty regarding final product purity, bio-propylene may be better suited to produce chemicals, such as isopropanol (fig. S1).

As mentioned above, RCF of birch also produces a carbohydrate pulp (65 wt \% on wood weight basis, composed of $<10 \mathrm{wt} \%$ of lignin, 60 wt \% of cellulose, and 19 wt \% of hemicellulose) and phenolic oligomers (30 wt \% on lignin weight basis). To ferment both glucose and xylose, the carbohydrate pulp was subjected to a semisimultaneous saccharificationfermentation process, reaching a $40.2 \mathrm{~g}$ liter $^{-1}$ ethanol titer using an enzyme mixture for saccharification and an engineered yeast strain (MDS130) under nonoptimized conditions (Fig. 3A and supplementary text ST9). Note that the presence of $\mathrm{Ru} / \mathrm{C}$, originating from the $\mathrm{RCF}$ unit, was tolerated during this biological conversion.
Although we chose conversion of pulp into bioethanol for demonstration, other applications such as (news)paper, cardboard (23), insulation materials (24), and other chemicals (e.g., isosorbide, 2,5-furandicarboxylic acid, and 1-butanol) are possible as well.

A market for RCF phenolic oligomers (as obtained as a residue after extraction) is currently nonexistent. Still, these oligomers have a high functionality content $(3.46 \mathrm{mmol}$ phenolic $\mathrm{OH} \mathrm{g}{ }^{-1}$ and $2.48 \mathrm{mmol}$ aliphatic $\mathrm{OH} \mathrm{g}^{-1}$ ) (fig. S6 and table S3), and they lack the original phenolic interunit ether linkages (fig. S5 and table S2). To improve the overall profitability and sustainability of our proposed biorefinery, we investigated the potential of these oligomers to substitute for fossil-based para-nonylphenol [a debated endocrine disruptor (25)] in lithographic printing ink. Ink production typically
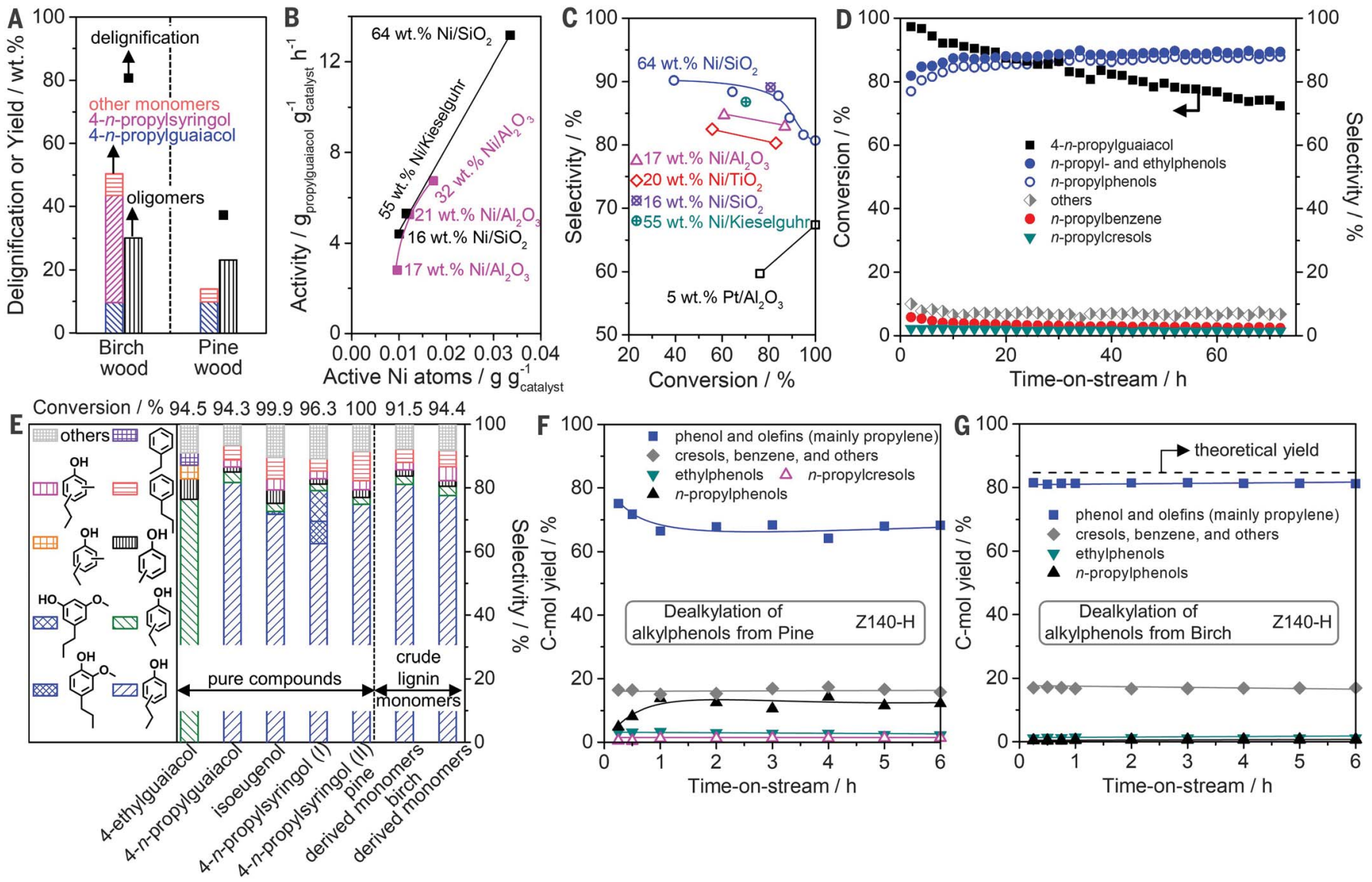

Fig. 2. RCF of wood and catalytic funneling of lignin monomers to phenol and propylene. (A) RCF of birch and pine wood to lignin monomer, oligomers, and carbohydrate pulp (details in supplementary materials). (B) Activity of selected supported $\mathrm{Ni}$ catalysts for hydroprocessing of $\mathrm{PG}\left(285^{\circ} \mathrm{C}\right.$ with low conversion $<20 \%$, the data are taken at time-on-stream of 3 hours). (C) Selectivity to PPs versus PG conversion $\left[285^{\circ} \mathrm{C}\right.$ at different weigh hourly space velocities (WHSVs)]. (D) Evolution of conversion and products selectivity with time-on-stream over 64 wt $\% \mathrm{Ni} / \mathrm{SiO}_{2}$ for hydroprocessing of $\mathrm{PG}\left(285^{\circ} \mathrm{C}\right.$ and 6.0 hour $^{-1}$ WHSV).

(E) Hydroprocessing of different lignin-derived phenolics (over 64 wt \% Ni/SiO 2 : $\mathrm{EG}, \mathrm{PG}$, isoeugenol, and pine-derived monomers at $285^{\circ} \mathrm{C}$ and $8.2,6.0,4.4$, and
6.0 hour $^{-1}$ WHSV, respectively; PS(I), PS(II), and birch-derived monomers at $305^{\circ} \mathrm{C}$ and $7.1,5.3$, and 5.3 hour $^{-1}$ WHSV, respectively). The data in (C) and (E) are taken at time-on-stream of 5 hours. Hydroprocessing constant reaction conditions: 1 bar of total pressure ( 0.4 bar of $\mathrm{H}_{2}$ partial pressure). Dealkylation of the hydroprocessing products from extracted (unseparated) mixture of monomers of $(\mathbf{F})$ pine and $(\mathbf{G})$ birch wood lignin oils at $410^{\circ} \mathrm{C}$ over $\mathrm{Z} 140-\mathrm{H}$ with time-on-stream at WHSV of 3.7 hour $^{-1}$ and 2.8 hour $^{-1}$, respectively. C-mol yield in $(F)$ and $(G)$ represents the carbon molar yield in the product stream. The theoretical yield $(84.7 \%)$ in $(G)$ is the maximum combined yield of phenol and olefins on the basis of the substrate composition (table S4). 

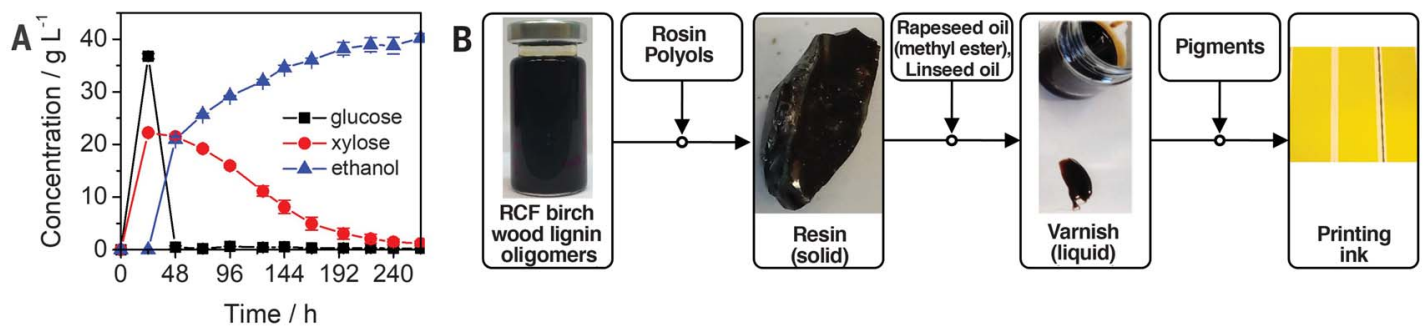

Fig. 3. Valorization of RCF birch wood carbohydrate pulp and phenolic oligomers. (A) Semisimultaneous saccharification-fermentation of carbohydrate pulp (containing Ru/C catalyst) obtained after RCF of birch wood. (B) Stepwise synthesis of ink from RCF birch wood lignin oligomers (details in supplementary materials).

involves a three-step procedure: (i) resin formation from rosin, polyols, and (nonyl)phenols; (ii) varnish production by adding rape- and linseed oil; and (iii) coloration by admixing pigments (Fig. 3B and figs. S38 and S39). The intermediate resin made from RCF birch wood lignin oligomers did meet industrial specifications, such as vacuum time and residue on filter (table S6, figs. S40 to S42, and supplementary text ST10). Next, the oligomer-based varnish formed a stable emulsion and showed similar water balance compared to para-nonylphenolbased as well as commercial resin-based ink varnish (table S7, figs. S43 and S44, and supplementary text ST10). Finally, yellow-colored lithographic printing ink was made by admixing the renewable RCF oligomer-based varnish with pigments (Fig. 3B). RCF oligomers outperformed other lignin derivatives, such as methanosolv birch wood lignin and commercial acetosolv spruce wood lignin. Substitution of nonylphenol with acetosolv spruce wood lignin failed because of phase incompatibility and the formation of observable black aggregates at the resin stage (supplementary text ST10). This case study underlines the unexplored market potential of RCF phenolic oligomers in highquality printing ink, in which they could serve as a renewable substitute for fossil-based nonylphenol.

On the basis of the experimental data, we designed a process model to perform a technoeconomic analysis (TEA) (Fig. 1 and fig. S45). The process model integrates the three catalytic steps: (i) RCF of wood, (ii) hydroprocessing of crude monomers extract, and (iii) dealkylation of the crude alkylphenol product stream. In the first catalytic step, RCF of birch wood produces a carbohydrate pulp and a lignin oil, the latter of which is obtained by liquid-solid separation and solvent recuperation. From the lignin oil, monomers are readily isolated in a liquid $n$-hexane extraction unit, followed by flash distillation to remove $n$-hexane. The crude monomers extract and the RCF off-gas-containing methane, which originates from the limited $\mathrm{MeOH}$ conversion in RCF, and $\mathrm{H}_{2}$-are fed to the second catalytic step. This gas-phase fixed-bed reactor contains the hydroprocessing catalyst, $\mathrm{Ni} / \mathrm{SiO}_{2}$, to yield alkylphenols. In the third catalytic step, this crude alkylphenol mixture, containing water, hydrogen, and methane impurities, is fed without intermediate purification to the second fixed-bed reactor. This setup contains the dealkylation catalyst (Z140-H) to yield phenol and olefins. The presence of the remaining hydrogen had no effect on the olefin formation (fig. S36). Next, product separation in a gas-liquid separator produces a liquid phenol stream and a gaseous mixture of water, olefins, $\mathrm{H}_{2}$, and $\mathrm{CH}_{4}$. Finally, to obtain high purity phenol and propylene, impurities such as cresols and benzene (in the phenol fraction) and $\mathrm{H}_{2} / \mathrm{CH}_{4}$ (in the olefin fraction) can be removed by distillation. In this model, side streams related to sugar solubilization (during RCF) and benzene and cresols formation end up in a wastewater stream. Methyl acetate, formed by methanolysis of the acetyl groups in (birch wood) hemicellulose, is largely separated in the methanol recovery distillation. Together with the excess $\mathrm{H}_{2}, \mathrm{CH}_{4}$, $\mathrm{C}_{2} \mathrm{H}_{4}$, and small amounts of methanol (also from distillation), methyl acetate is incinerated to provide heating, cooling, and electricity through a trigeneration system. The addition of external energy is not required to operate the integrated biorefinery. Overall, this process model design converts $1000 \mathrm{~kg}$ of birch wood into $653 \mathrm{~kg}$ of raw carbohydrate pulp (for bioethanol), $64 \mathrm{~kg}$ of lignin oligomers (for printing ink), $42 \mathrm{~kg}$ of phenol, and $20 \mathrm{~kg}$ of propylene (>99\%), which corresponds to a conversion of $78 \mathrm{wt} \%$ of the initial biomass into targeted products (figs. S46 and S47 and table S8). Possible solvent losses were studied, indicating a maximum loss of $1.4 \%$ of methanol due to (i) distillation, (ii) hydrogenolysis during RCF, and (iii) incorporation into products (supplementary text ST11).

The TEA of our proposed biorefinery was calculated for an annual production of 100 kilotons of bio-phenol (i.e., the average scale for fossil-based phenol production). Among the different process units, RCF and incinerationtrigeneration are the highest contributors toward capital expenditures because of the high cost of pressure reactors and energy integration, respectively (fig. S48 and supplementary text ST12). Investing in an incineration-trigeneration unit is justified, however, by its positive effect on the manufacture cost because of markedly reduced energy costs. The highest contribution to the manufacturing cost is the cost of feedstock (birch wood, 158 euros per ton; tables S9 and S10). Given the current pricing (table S9) of phenol (1300 euros per ton), propylene (830 euros per ton), and crude pulp (400 euros per ton), and using an estimate for the oligomers (1750 euros per ton, approaching that of nonylphenol), this results in an internal rate of return of $23 \%$ and a payout time of $\sim 4$ years for a plant with a lifetime of 20 years (table S11). A sensitivity study indicates that feedstock and product pricing have the largest economic effect (fig. S49 and supplementary ST12), whereas the influence of catalyst cost is negligible as long as the catalyst is sufficiently recyclable or reusable. In terms of RCF process parameters, shorter contact times and higher biomass concentrations are crucial factors to improve the profitability of this biorefinery, which implies the need to design a dedicated reactor.

The production of chemicals from biomass makes sense only if a lower $\mathrm{CO}_{2}$ footprint is achieved. Thus, in addition to a TEA, we performed a life-cycle assessment (LCA). Our proposed integrated birch wood biorefinery showed reduced global warming potentials (GWPs) for phenol (0.736 kg of $\mathrm{CO}_{2}$-equivalent per kilogram of phenol) and propylene $\left(0.469 \mathrm{~kg}\right.$ of $\mathrm{CO}_{2}$ equivalent per kilogram of propylene) compared with their fossil-based counterparts (1.73 and $1.47 \mathrm{~kg}$ of $\mathrm{CO}_{2}$-equivalent per kilogram of phenol and propylene, respectively; open and red symbols in Fig. 4, A and B, supplementary text ST13, and tables S12 to S14). Moreover, the GWP of the oligomers (proposed as a substitute for para-nonylphenol with a GWP of $>1.58 \mathrm{~kg}$ $\mathrm{CO}_{2}$-equivalent per kilogram of nonylphenol) and the carbohydrate pulp were calculated to be -0.949 and $-0.217 \mathrm{~kg}$ of $\mathrm{CO}_{2}$-equivalent per kilogram of oligomers and carbohydrate pulp, respectively (open symbols in Fig. 4, A and $\mathrm{B}$ ). These negative values indicate a net consumption of $\mathrm{CO}_{2}$, that is, a net carboncapturing effect for their production. Finally, to indicate opportunities for sustainability improvement, additional scenarios were analyzed, such 

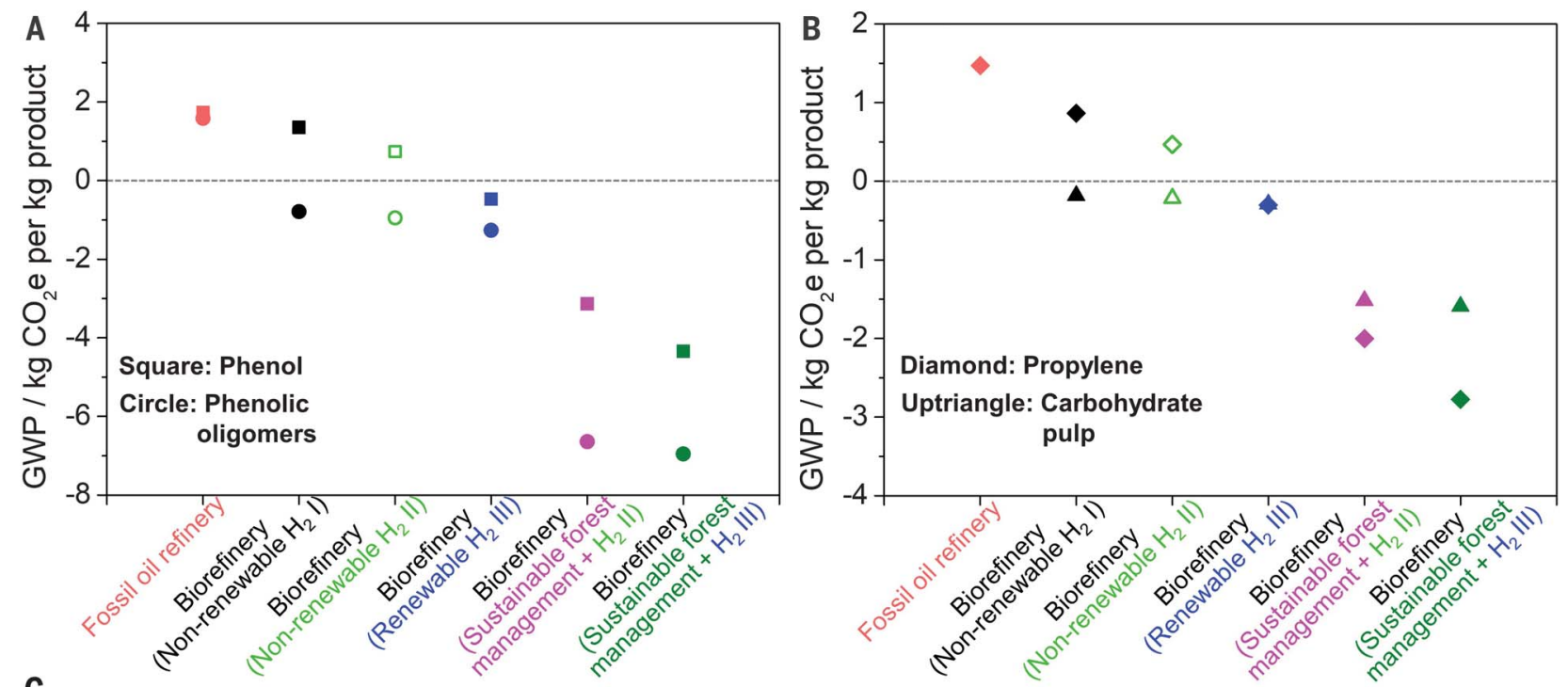

C

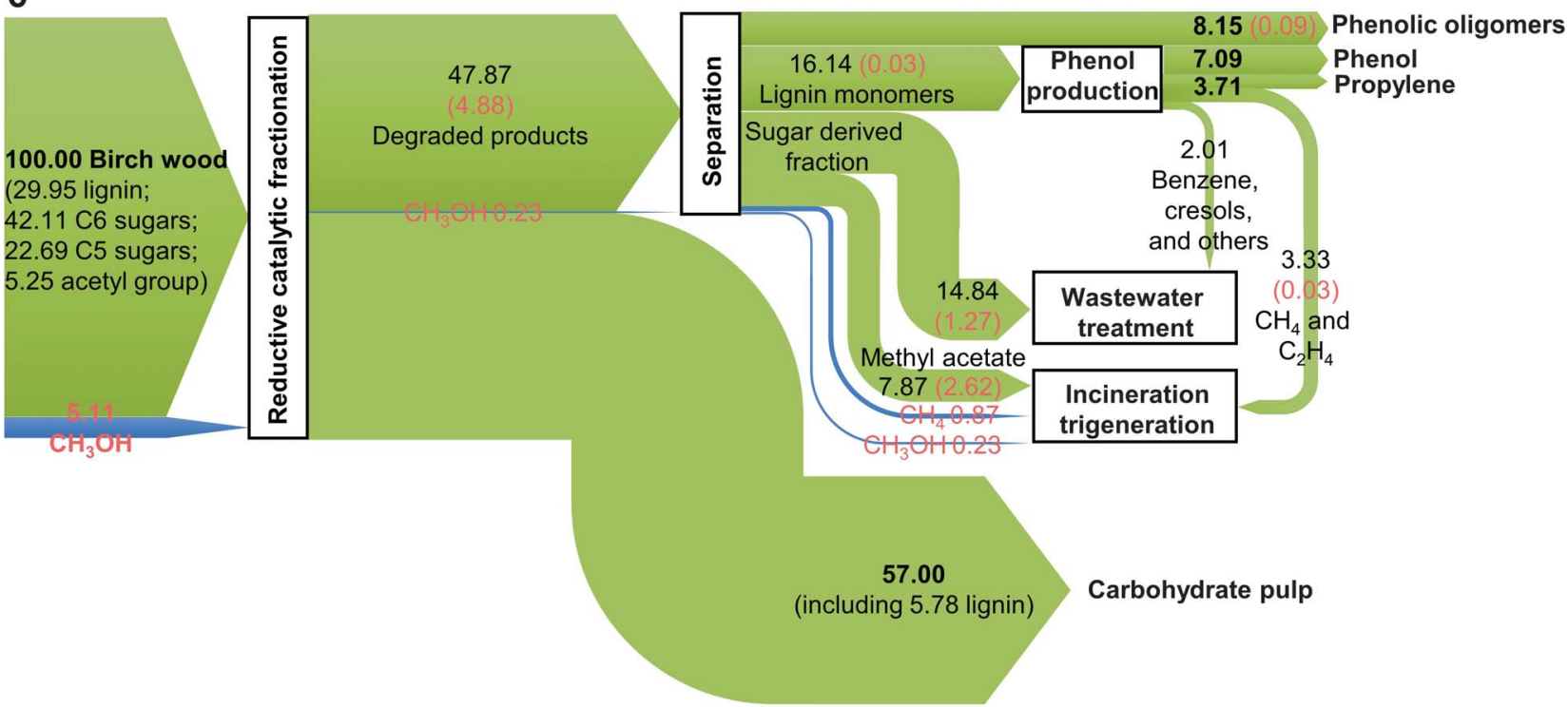

Fig. 4. LCA and carbon flow for the proposed integrated biorefinery based on birch wood. ( $\mathbf{A}$ and $\mathbf{B}$ ) GWPs [in kilograms of $\mathrm{CO}_{2}$-equivalent per kilogram of product ( $\mathrm{kg} \mathrm{CO}_{2} \mathrm{e}$ per kg product)] of phenol, propylene, phenolic oligomers, and carbohydrate pulp in this birch wood biorefinery with different scenarios (i.e. several hydrogen sources and/or forest management strategies). The GWPS are $11.89,8.20$, and $0.97 \mathrm{~kg}$ of $\mathrm{CO}_{2}$-equivalent per kilogram of $\mathrm{H}_{2}$ for nonrenewable $\mathrm{H}_{2} \mathrm{I}$, nonrenewable $\mathrm{H}_{2} \mathrm{II}$, and renewable $\mathrm{H}_{2} \mathrm{III}$, respectively (see supplementary materials). The GWP of phenolic oligomers from oil refining is the GWP of fossil-based nonylphenol ( $>1.58 \mathrm{~kg}$ of $\mathrm{CO}_{2}$-equivalent per kilogram of nonylphenol). (C) Carbon flow of this birch wood biorefinery. as, (i) the substitution of nonrenewable $\mathrm{H}_{2}$, which has a high $\mathrm{CO}_{2}$ contribution, by renewable $\mathrm{H}_{2}$ and (ii) the inclusion of more sustainable forest management (Fig. 4 and fig. S52). Such integration scenarios unveil the possibility for $\mathrm{CO}_{2}$-neutral wood biorefining with a total net consumption of $\mathrm{CO}_{2}$ (i.e., negative GWP values) for each targeted product.

On the basis of the proposed integrated biorefinery, 78 and $76 \%$, respectively, of the initial mass and carbon content of birch wood can be economically and sustainably valorized into four high-value end-products, namely phenol, propylene, oligomers, and pulp (Fig. 4C and fig. S47). In our opinion, this process will constitute a clear incentive to make profitable, renewable, low-carbon footprint chemicals via the holistic biorefining of sustainable wood.

\section{REFERENCES AND NOTES}

1. J.-F. Bastin et al., Science 365, 76-79 (2019).

2. K. Van Meerbeek, B. Muys, M. Hermy, Renew. Sustain. Energy Rev. 102, 139-149 (2019)

3. T. Werpy, G. Petersen, "Top value added chemicals from biomass: Volume I-Results of screening for potential candidates from sugars and synthesis gas" (National Renewable Energy Laboratory, 2004); www.osti.gov/biblio/ 15008859.

4. J. E. Holladay, J. F. White, J. J. Bozell, D. Johnson, “Top valueadded chemicals from biomass: Volume II-Results of screening for potential candidates from biorefinery lignin"
(Pacific Northwest National Laboratory, 2007); www.osti.gov/ biblio/921839

5. A. Kätelhön, R. Meys, S. Deutz, S. Suh, A. Bardow, Proc. Natl. Acad. Sci. U.S.A. 116, 11187-11194 (2019)

6. International Energy Agency, "The future of petrochemicals: Towards more sustainable plastics and fertilisers" (IEA Publications, 2018); www.connaissancedesenergies.org/sites/ default/files/pdf-actualites/the_future_of_petrochemicals.pdf.

7. D. M. Alonso et al., Sci. Adv. 3, e1603301 (2017).

8. A. J. Ragauskas et al., Science 344, 1246843 (2014).

9. C. Li, X. Zhao, A. Wang, G. W. Huber, T. Zhang, Chem. Rev. 115 , 11559-11624 (2015).

10. Z. Sun, B. Fridrich, A. de Santi, S. Elangovan, K. Barta, Chem. Rev. 118, 614-678 (2018)

11. J. G. Linger et al., Proc. Natl. Acad. Sci. U.S.A. 111, 12013-12018 (2014).

12. I. Kumaniaev et al., Green Chem. 19, 5767-5771 (2017).

13. E. M. Anderson et al., Joule 1, 613-622 (2017).

14. W. Schutyser et al., Chem. Soc. Rev. 47, 852-908 (2018) 
15. Q. Song et al., Energy Environ. Sci. 6. 994-1007 (2013).

16. S. Van den Bosch et al., Energy Environ. Sci. 8, 1748-1763 (2015).

17. A. Vuori, J. B. Bredenberg, Holzforschung 38, 253-262 (1984).

18. N. Joshi, A. Lawal, Ind. Eng. Chem. Res. 52, 4049-4058 (2013)

19. H. L. Chum, D. K. Johnson, S. Black, M. Ratcliff, D. W. Goheen, in Advances in Solar Energy: An Annual Review of Research and Development, K. W. Böer, Ed. (Springer, 1988), pp. 91-200.

20. X. Liu et al., ChemSusChem 12, 4791-4798 (2019).

21. D. Verboekend, Y. Liao, W. Schutyser, B. F. Sels, Green Chem 18, 297-306 (2016)

22. Y. Liao et al., ACS Catal. 8, 7861-7878 (2018).

23. H. Sixta, Handbook of Pulp (Wiley, 2006).

24. S. Schiavoni, F. D'Alessandro, F. Bianchi, F. Asdrubali, Renew. Sustain. Energy Rev. 62, 988-1011 (2016).

25. A. Soares, B. Guieysse, B. Jefferson, E. Cartmell, J. N. Lester, Environ. Int. 34, 1033-1049 (2008).

\section{ACKNOWLEDGMENTS}

We thank W. Vermandel for his assistance in producing lignin oil and R. Ooms and J. Maes for technical assistance during the catalytic testing. Funding: Y.L., G.V.d.B., D.V., J.V.A., and B.L. acknowledge funding from the China Scholarship Council (201404910467), Catalisti-ICON project MAIA (Flemish government), Fonds Wetenschappelijk Onderzoek - Vlaanderen
(FWO) (postdoc), Flanders Innovation \& Entrepreneurship (innovation mandate - postdoc), and the Industrial Research Fund KU Leuven (IOF fellow), respectively. S.F.K. acknowledges Catalisti CSBO ARBOREF and BIO-HArT (Interreg VA Vlaanderen-Nederland) funding from the Flemish government. K.V.Ae. acknowledges funding from FWO-SBO project Biowood (S003518N). T.R. acknowledges KU Leuven internal research funds for a postdoctoral mandate (PDM). S.V.d.B. acknowledges funding from $\mathrm{KU}$ Leuven internal research funds for a PDM, the Flemish government for the FWO-SBO project Biowood, and Flanders Innovation \& Entrepreneurship (innovation mandate - postdoc). T.N. and J.M.T. acknowledge ARBOREF. Funding by BIOFACT (FNRS - FWO EOS project GOHO918N), supporting lignin conversion, is also acknowledged. Author contributions: Y.L. and B.F.S. conceived the idea and designed the experiments. Y.L. carried out the experimental work of the main catalysis research, and catalyst characterization and interpretation was assisted by D.V. S.-F.K. performed the liquid-liquid extraction separation work. G.V.d.B. and T.R. performed and interpreted the wood composition analysis and the processing experiments, according to the lignin-first concept, and the preparation and analysis of a large batch of isolated lignin-first phenolic monomers. J.V.A., S.V.d.B., and B.L. composed and focused on the TEA with the kind assistance of Exyte. K.N. and K.V.Ac. performed the LCA. T.N. and J.M.T. performed the fermentation of the lignin-first carbohydrate pulp to bioethanol. K.V.Ae. conducted the characterization and analysis of phenolic oligomers. M.M. and H.M. performed the production and characterization of the renewable resin and ink varnish. The text was initially composed by B.F.S., Y.L., S.-F.K., and G.V.d.B., and all authors further contributed to the discussion of the experimental work and the final version of the manuscript. Competing interests: Y.L., B.F.S., J.V.A., and S.V.d.B. are inventors on a patent application [attorney docket number 292-P15233US (ZL919134)], held and submitted by KU Leuven, that covers lignocellulose refinery. Data and materials availability: All data needed to support the conclusions of this manuscript are included in the main text or supplementary materials. 